\title{
The Life Condition of Syrian Asylum Seekers in Turkey and the Effect of These Conditions on the Desire to Migrate to Europe
}

\author{
Ersin Uygun $\bowtie$ \\ Refugee Mental Health Outpatient Clinic, University of Health Sciences, Bakırköy Mental Health and Nervous Diseases Training and \\ Research Hospital, İstanbul, Turkey
}

Objective In recent years, many Syrian asylum seekers has died while they were crossing over sea to migrate to Europe. We aimed to identify the determinants of choice of Syrian asylum seekers for emigration to Europe; therefore, we selected the sample from refugee mental health clinic in Turkey.

Methods Our sample consists of 100 Syrian who applied to the refugee mental health branch polyclinic. Participants filled out the (e1) sociodemographic form, WHO-5 well-being index, and WHOQL. Then their future plans assessed by the interviewer.

Results It was seen that people who prefer to emigrate to Europe have higher level education level, lower income status, and had worse physical conditions at home. Also, They live generally in urban area, they do not have close relatives living in Syria, have poor mental well-being and have low quality of life scores. Job duration, absence of close relatives living in Syria, having low WHOOL score and physical conditions of home were found significant in regression analysis.

Conclusion We found that their economic circumstances significantly predicted their preference, unlike clinical variables. We believe in that, improving their economic conditions and the life quality of Syrian asylum seekers can prevent illegal migration by dangerous routes to Europe and policy makers over the world should consider this situation.

Psychiatry Investig 2020;17(1):55-60

Key Words Asylum seekers, Europe, Migration, Syrian refugees, Trauma.

\section{INTRODUCTION}

Many people displaced in recent years and trying to go to Europe is increasing day by day. ${ }^{1}$ The armed conflict in Syria which began in 2011 has resulted in a massive forced displacement of the Syrian population. According to the UNCHR by the end of June 2018, there were approximately 5.6 million registered Syrian asylum seekers. ${ }^{2}$ The majority of Syrian asylum seekers have fled Syria for neighbouring countries. Turkey now hosts about 3.6 million Syrian asylum seekers. ${ }^{3}$

Refugees are a high-risk group for developing mental health difficulties as their exposure to adversity and trauma is associ-

Received: December 29, 2018 Revised: April 28, 2019

Accepted: October 1, 2019

$\triangle$ Correspondence: Ersin Uygun, MD

Refugee Mental Health Outpatient Clinic, University of Health Sciences, Bakırköy Mental Health and Nervous Diseases Training and Research Hospital, Doktor Tevfik Sağlam Cd. 25/2, 34147 Bakırköy, İstanbul, Turkey

Tel: +90-5058512303, Fax: +90-212 40915 95, E-mail: ersinuygun@hotmail.com

(c) This is an Open Access article distributed under the terms of the Creative Commons Attribution Non-Commercial License (https://creativecommons.org/licenses/by$\mathrm{nc} / 4.0$ ) which permits unrestricted non-commercial use, distribution, and reproduction in any medium, provided the original work is properly cited. ated with a range of negative psychological outcomes.-6 Many studies have shown that traumatic experiences and discrimination affect mental health of refugees ${ }^{7-9}$ and predisposes them to many mental disorder. ${ }^{10}$ Similar to other refugee populations, thousands of Syrians are being subjected to difficulties (or potentially traumatic experiences) on their journey to $\mathrm{Eu}-$ rope. ${ }^{11}$

Syrian asylum seekers who arrived in Turkey try to go to other countries that can provide better conditions by dangerous journeys. During 2015 and 2016, an unprecedented influx of more than 750,000 Syrian asylum seekers went from Turkey to Western Europe by using Balkans route. ${ }^{12}$ In 2018, The Refugee Rights Sub Commission of Turkish Grand National Assembly reported that, the number of refugees crossing the Aegean sea into Greece by the date of 18 March 2016 is around one thousand people per day. ${ }^{13}$ In 2017, a total of 23,754 irregular migrants were seized by the Coast Guard Command and other law enforcement units; in the same period 22,515 irregular migrants were arrested by Greece and the majority of these immigrants were Syrian. ${ }^{13}$ Organizers of human trafficking confiscate their money by cheating migrants; they put their lives in danger by putting too many im- 
migrants into boats with unsafe methods. ${ }^{13}$ Syrian asylum seekers who are trying get into Europe can die during this journey. The Coast Guard commander reported that only 192 immigrants in 2017 lost their lives while attempting to illegally cross through Aegean Sea route. ${ }^{13}$

Since human alive, they are on the move, but it has been fuelled in recent years by increasing in conflict, climate change and the opportunities and pressures of globalisation. ${ }^{14}$ Today, migration is a combination of economically capable personality, physically sound, with the perception of the world as being threatening and a sharpened sense of danger. ${ }^{15}$ On the other hand, migration includes not just arrival in a host country but also preparation for departure and the journey itself. Each phase can have both short-term and long-term impact on the migrants' well-being (e.g. living in poverty; being a victim of violence, torture or rape).

In this study, we aimed to identify the psychosocial determinants of choice of Syrian asylum seekers who migrate to Europe even from illegal ways or stay in Turkey. The sample was selected from refugee mental health branch clinic. We have hypothesized that, bad economic situations, poor psychosocial conditions and poor mental health can affect the decision of emigration to Europe.

\section{METHODS}

\section{Participants and procedures}

Our sample consists of the Syrian volunteers who applied to the immigrant and refugee mental health special branch polyclinic of Bakırköy Mental Health and Neurological Diseases Training and Research Hospital (BRSHH) for the psychiatric complaints between 1 January and 1 April 2017. Between two dates, volunteers who applied to our clinic were informed about the study and the sample was randomly selected to follow-up work. Those who did not give consent or were unable to answer questions were not included in the study. The questionnaires were conducted by the psychiatric specialist whose native language is Arabic and has knowledge about Syrian culture.

The study took place at BRSHH, a mental health hospital with approximately 1,600 beds which is located in İstanbul, the largest city in Turkey. According to the Ministry of Interior Directorate General of Migration Management as of 24.05.2018, there are 560.959 Syrians registered in İstanbul. The refugee special branch polyclinic is located in this hospital and open on Wednesdays. It only serves the Syrian people.

The study was approved by local ethics committee of BRSHH by "632" reference number in 07.02.2017. In order to receive the health services, Syrian asylum seekers who applied for the BRSHH refugee mental health special polyclinic were informed about the study after the health service was first provided and they were asked whether they would like to participate in the study. The volunteers who gave the consent were interviewed in a separate room and asked the questions that were included in the Sociodemographic form. After the questions, they were asked to fill out the psychological well-being scales. The Questions was read to participant who is illiterate. After this process, participants were asked where they planned their future.

\section{Assessment of sociodemographic features}

Data collection form was created by the researchers and used to determine the physical conditions of the house, how many people live in the house and how far the house is from the city centre. Besides, the questions about age, gender, educational status, income situation, employment status, and how many public transport vehicles use to reach the hospital were asked.

\section{Measurement of well-being}

WHO-Five well-being Index has used to assess well-being. The WHO-Five was originally designed by the World Health Organization for the assessment of well-being among diabetic patients. ${ }^{16}$ Items are rated on a 6-point scale ranging from 'all of the time' (5) to 'at no time' (0), resulting in a maximum sum score of 25 . The validation of Arabic version of the index was conducted by Sibai et al. ${ }^{17}$

\section{Measurement of life quality}

WHO-Quality of Life Questionnaire was used to measure the life quality of participants. The WHOQOL-BREF is a 26item, self-administered, and generic questionnaire that is a short version of the WHOQOL-100 scale. ${ }^{18}$ The response options range from 1 (very dissatisfied/very poor) to 5 (very satisfied/very good). Assessments are made over the preceding two weeks. Ohaeri et al. ${ }^{19}$ has done the reliability and validity study of the short version of the WHO Quality of Life Instrument in an Arab general population.

\section{Statistical analysis}

Data entered into the database created in SPSS 20.0 version (IBM Corp., Armonk, NY, USA). Firstly, descriptive statistics of variables were analysed. The data were evaluated by the Kolmogorov-Smirnov test for normal distribution and normal distributions were observed. For comparing the future plan and categorical variables, chi-square test was used. Future plan and the parametric variables were analysed by independent student t-test. Logistic regression (enter model) analysis was used to determine the determinants of preference for going to Europe, a dependent variable for preferring 
to go to Europe for identification, and factors that showing a significant difference between the two groups and reflecting the quality of life, economic conditions as independent variables.

\section{RESULTS}

118 Syrians applied to our clinic between the dates specified. Six of them stated that they had no time to participate in the study. Ten people were hospitalized because of their mental illness, their symptoms get worse so they were not involved in the study. The information of two people is not entered in the database due to missing information in their scale forms. Therefore, the sample included 54 women (54\%) and 46 men (46\%). The average age of the participants was 33.8 years (s.d.: \pm 11.7 ), the education level was 8.21 years (s.d.: \pm 3.84 ), the room in the house where she/he lived/person rate average was 0.39 (s.d.: \pm 0.2 ), mean score of WHO-Five Wellbeing index score was 12.8 (s.d.: \pm 6.5 ), mean score of quality of life scale was 118.7 (s.d.: \pm 37.4 ), mean duration of symptoms were 48.2 months (s.d.: \pm 77.9 ) and similarly the average duration time in Turkey was 48.2 months (s.d.: \pm 77.9$)$ (Table 1). While 69 participants (69\%) did not work anywhere, 41 (41\%) were single, 46 (46\%) were married and 13 (13\%) per-

Table 1. Sociodemographic and clinical data of participants

\begin{tabular}{|c|c|}
\hline 100 participant & $\mathrm{N}(\%)$ \\
\hline \multicolumn{2}{|l|}{ Gender } \\
\hline Female & $54(54)$ \\
\hline Male & $46(46)$ \\
\hline \multicolumn{2}{|l|}{ Marital status } \\
\hline Single & $41(41)$ \\
\hline Married & $46(46)$ \\
\hline Other & $13(13)$ \\
\hline \multicolumn{2}{|l|}{ Working status } \\
\hline Unemployed & $69(69)$ \\
\hline Employed & $21(21)$ \\
\hline 100 participant & Mean \pm SD \\
\hline Age & $33.8 \pm 11.7$ \\
\hline Education (year) & $8.21 \pm 3.84$ \\
\hline Room/person ratio & $0.39 \pm 0.2$ \\
\hline WHO-Five Well-being Index score & $12.8 \pm 6.5$ \\
\hline $\begin{array}{l}\text { Number of public transit vehicles used to come } \\
\text { to the hospital }\end{array}$ & $1.7 \pm 0.75$ \\
\hline Duration of symptom (month) & $48.2 \pm 77.9$ \\
\hline Quality of life scale score & $118.7 \pm 37.4$ \\
\hline Duration in Turkey (month) & $48.2 \pm 77.9$ \\
\hline
\end{tabular}

WHO: World Health Organization, SD: standart deviation son were divorced or widowed (Table 1).

Comparing the participants who prefer to plan their future in Europe and those who do not, it was found that people prefer to migrate to Europe have significantly less close relatives living in Syria (t: 9.84 and $\mathrm{p}=0.002)$, more highly educated (t: -3.9 and $\mathrm{p}=0.0001$ ), low income status ( $\mathrm{t}: 8.2$ and $\mathrm{p}=0.016$ ), less living rooms in the house/person ratio ( $\mathrm{t}: 3.28$ and $\mathrm{p}=0.018$ ), low WHO-Five Well-being index scores (t: 3.99 and $\mathrm{p}=0.0001$ ), higher number of transportation vehicles to go to the refugee mental health branch clinic ( $\mathrm{t}:-2.18$ and $\mathrm{p}=0.032$ ), less duration of symptoms ( $\mathrm{t}: 2.26$ and $\mathrm{p}=0.026$ ) and low quality of life (t: 5.63 and $\mathrm{p}=0.0001$ ). On the contrary, having experienced severe mental trauma ( $\mathrm{t}: 1.02$ and $\mathrm{p}=0.44)$, gender (t: 1.38 and $\mathrm{p}=0.27$ ), marital status ( $\mathrm{t}: 3.06$ and $\mathrm{p}=0.54$ ), working status (t: 1.06 and $\mathrm{p}=0.41$ ), job seeking (t: 1.07 and $\mathrm{p}=0.36$ ), age ( $\mathrm{t}: 0.8$ and $\mathrm{p}=0.42$ ), the socioeconomic status in Syria ( $\mathrm{t}$ : 8.28 and $p=0.16$ ), the number of children ( $t: 0.80$ and $p=0.24$ ) and the period spent in Turkey ( $\mathrm{t}: 2.41, \mathrm{p}=0.17$ ) were not significantly different (Table 2).

To assess the factors that determine the choice of going to Europe, variables which showing significant differences between the two groups were taken as independent variables in logistic regression analysis. In the logistic regression analysis, we found that the high education level, low income status, the absence of close relatives in Syria, the low quality of life scale score and the low ratio of the room/person living in the house determined the future planning preference in Europe statistically significantly (Table 3 ).

\section{DISCUSSION}

In our study, we examined the factors related to the preference for structuring future experiences of patients who applied to the refugee/immigrant mental health branch policlinic of the Bakırköy Mental Health and Neurological Diseases Training and Research Hospital. That part has revised as; "In our study we found that, in the group who prefer to go to Europe the level of education was higher, income level was low, there weren't close relatives living in Syria, the quality of life score was low, the conditions of the house were worse, WHO well-being index score was low, duration of the symptoms were shorter than other group." Moreover, we found that the number of vehicles used to go to the hospital showing the distance of the place to the centre of the city is highest in the group who prefer to go to Europe.

A limited number of asylum seekers in European countries to accept the legally determined every year and Syrians can apply for it to the UN headquarters in Turkey. However, more than the determined number of refugees want to go to these countries; therefore, these individuals resort to illegal 
Table 2. Compare of participants who are planning and who are not planning to migrate to Europe

\begin{tabular}{|c|c|c|c|c|c|}
\hline 100 participant & & Europe (-) & Europe $(+)$ & $\mathrm{p}$ & Test value \\
\hline \multirow[t]{2}{*}{ Psychological trauma } & Yes & 52 & 24 & 0.44 & 1.02 \\
\hline & No & 19 & 5 & & \\
\hline \multirow[t]{2}{*}{ Presence of close relative living in Syria } & Yes & 66 & 20 & 0.002 & -9.84 \\
\hline & No & 5 & 9 & & \\
\hline \multirow[t]{2}{*}{ Gender } & Female & 41 & 13 & 0.27 & 1.38 \\
\hline & Male & 30 & 16 & & \\
\hline \multirow[t]{3}{*}{ Marital status } & Single & 29 & 12 & 0.54 & 3.06 \\
\hline & Married & 33 & 13 & & \\
\hline & Other & 9 & 4 & & \\
\hline \multirow[t]{2}{*}{ Employment status } & Unemployed & 58 & 21 & 0.41 & 1.06 \\
\hline & Employed & 13 & 8 & & \\
\hline \multirow[t]{2}{*}{ Job search status } & Looking for work & 24 & 13 & 0.36 & 1.07 \\
\hline & Not looking & 47 & 16 & & \\
\hline Age & Mean & 34.4 & 32.3 & 0.42 & 0.8 \\
\hline Education (year) & Mean & 7.2 & 10.4 & 0.0001 & 3.98 \\
\hline \multirow[t]{2}{*}{ Income status in Turkey } & Debt & 42 & 25 & 0.016 & -8.2 \\
\hline & Equal & 29 & 4 & & \\
\hline \multirow[t]{3}{*}{ Status in Syria } & Upper class & 19 & 2 & 0.16 & 8.28 \\
\hline & Middle class & 32 & 11 & & \\
\hline & Sub class & 20 & 16 & & \\
\hline Room/person ratio & Mean & 0.42 & 0.32 & 0.018 & -3.28 \\
\hline WHO-Five Well-being Index score & Mean & 14.4 & 9 & 0.0001 & -3.99 \\
\hline Number of children & Mean & 2.16 & 2.03 & 0.804 & 0.24 \\
\hline Number of public transit vehicles used to come to the hospital & Mean & 1.6 & 2.03 & 0.032 & 2.18 \\
\hline Duration of symptom (month) & Mean & 56.7 & 27.3 & 0.026 & -2.26 \\
\hline Quality of life scale score & Mean & 130.5 & 89.9 & 0.0001 & -5.63 \\
\hline Duration in Turkey (month) & Mean & 37.5 & 32 & 0.17 & 2.41 \\
\hline
\end{tabular}

$\mathrm{p}<0.05$ indicates statistical significance. WHO: World Health Organization

means. In the literature search, it has been seen that there is lack of studies related to the reasons of the motivation of Syrian asylum seekers to go to Europe and in this respect, our work is the first study to question it in our country.

In our study, income status, room person rate, number of public transportation vehicles changed from arrival to hospital, and quality of life were found as variables showing significant difference between the two groups. These variables can be assessed under the heading of economic difficulties. In a study conducted in Isparta, one of the city in Turkey, with asylum seekers living in economic hardship of the participants reported that they experienced significant $97 \% .{ }^{20}$ It is also emphasized in the article that low income level negatively affects mental health..$^{21}$ This finding suggests that the difficulties in the economic environment are important variables determining the preference for going to Europe. However,
Steel et al. ${ }^{22}$ examined the challenges of immigration in Sweden and found that the most common difficulties were separation from family and economic difficulties. Zaazaa, ${ }^{23}$ in fact recently mentioned that some Syrians asylum seekers came back to Turkey from Europe with unmet expectations towards Europe and stressed that they expressed in the form we've run chasing a dream did not come true for returning asylum seekers. ${ }^{23}$ We think that this situation should be examined with further studies with the Syrians settled in Europe. In our study, we also found that patients who wanted to go to Europe had worse mental well-being. Although economic conditions are associated with low self-esteem, mental well-being and life satisfaction in healthy host population, ${ }^{24,25}$ the literature suggests that the relationship between economic difficulties and mental well-being is stronger for refugees. ${ }^{26}$ In our work, we have found that the higher level of educa- 
Table 3. Logistic regression analysis of variables that can be effect emigrate to Europe

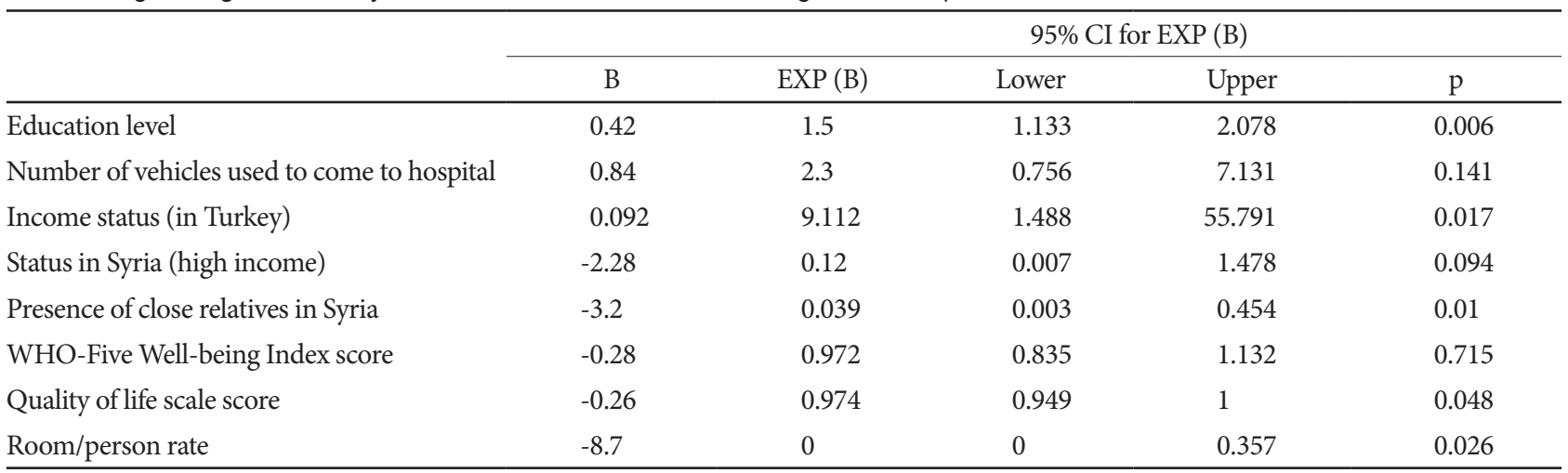

Omnibus tests of model: $\mathrm{p}=0.0001$ and $\mathrm{r}=0.70$. $\mathrm{p}<0.05$ is indicate statistical significance. WHO: World Health Organization

tion has significantly contributed to the preference for going to Europe. We have also seen that individuals who have a short duration of symptoms, unlike those who have been ill for a long time, want to go further to Europe in a meaningful way. Pajic et al. ${ }^{27}$ emphasized the importance of the self-efficacy of Syrian refugees located in the Netherlands and Greece in job seeking and reported that more self-efficacious individuals had more confidence in job search behaviour in the target country and more adapted to career conditions. In addition, in their study with Kurdish and Afghan refugees, Sulaiman-Hill and Thompson found that greater self- efficacy was associated with lower psychological distress, as well as with positive educational and employment outcomes in refugees. ${ }^{28,29}$ Moreover, Cengiz et al. ${ }^{30}$ has found that, high education level was associated with high psychological resilience in Syrian asylum seekers in Turkey. Education level and long-term (chronic) self-efficacy and resilience of mental illness has been associated with considering factors affecting the choice to go to Europe is likely to occur via different mechanisms.

\section{Conclusions and recommendations}

In conclusion, when the participants who did not want to go to Europe and did want to go to Europe were compared, the clinical variables such as duration of symptoms, mental wellbeing and income level, room/individual ratio, variables indicating the economic difficulties such as the quality of life are significantly different. However, we found that economic variables significantly predicted this preference, unlike clinical variables. We believe in that, improving economic conditions and the life quality of asylum seekers can prevent illegal migration to Europe from dangerous routes and policy makers should consider this situation.

\section{Limitations}

The fact that this study is at one centre and the absence of the control group constitutes the main limitations. Furthermore, the fact that, the sample is selected from clinical condition, it is difficult to generalize to all society. Moreover, other limitations are that; the study has descriptive nature with small sample size and a short questionnaire was used to assess mental health and well-being. Finally, we did not control the sample for diagnosis.

\section{Acknowledgments}

Special thanks to Ceren Acartürk, Șevval Bașar and Melike Kızıldoğan for their contributions to this study.

\section{Conflicts of Interest}

The author has no potential conflicts of interest to disclose.

\section{ORCID iD}

Ersin Uygun

https://orcid.org/0000-0003-3268-119X

\section{REFERENCES}

1. Tribe RH, Sendt KV, Tracy DK. A systematic review of psychosocial interventions for adult refugees and asylum seekers. J Ment Health 2017;9:1-15

2. UNHCR Report. 2018 Critical Funding Needs UNHCR Urgently Requires Some USD 452 Million to Address the Most Acute and Pressing Needs of Syrian Refugees in Turkey, Lebanon, Jordan, Iraq, and Egypt, and Internally Displaced Persons (IDPS) in Syria. Geneva: UNHCR; 2018.

3. UNHCR Europe Monthly Report-April 2018. Available at: http://reliefweb.int/sites/reliefweb.int/files/resources/58868.pdf. Accessed December 2, 2018.

4. Fazel M, Wheeler J, Danesh J. Prevalence of serious mental disorder in 7000 refugees resettled in western countries: a systematic review. Lancet 2005;365:1309-1314.

5. Taylor BE, Chekaluk E, Bennett J. Post-traumatic stress disorder, depression and anxiety among North Korean refugees: a meta-analysis. Psychiatry Investig 2017;14:550-561.

6. Lee YJ, Jun JY, Lee YJ, Park J, Kim S, Lee SH, et al. Insomnia in north Korean refugees: association with depression and post-traumatic stress symptoms. Psychiatry Investig 2016;13:67-73.

7. James R, Fazil Q. The epidemiology of PTSD and depression in refugee minors who have resettled in developed countries. J Ment Health 2017;26:74-83. 
8. Ayub M, Mushtaq I, Mushtaq S, Hafeez MA, Helal N, Irfan M, et al. Domestic violence, mental illness and suicidal ideation-A study from Lahore, Pakistan. J Ment Health 2013;22:474-481.

9. Noh JW, Park H, Kim M, Kwon YD, Kim JS, Yu S. The effects of discrimination experience on life satisfaction of North Korean refugees: mediating effect of stress. Psychiatry Investig 2018;15:49-53.

10. Turrini G, Purgato M, Ballette F, Nosè M, Ostuzzi G, Barbui C. Common mental disorders in asylum seekers and refugees: umbrella review of prevalence and intervention studies. Int J Ment Health Syst 2017;11;51.

11. Jefee-Bahloul H, Bajbouj M, Alabdullah J, Hassan G, Barkil-Oteo A. Mental health in Europe's Syrian refugee crisis. Lancet Psychiatry 2016;3:315-317.

12. Arsenijević J, Burtscher D, Ponthieu A, Severy N, Contenta A, Moissaing S, et al. "I feel like I am less than other people": health-related vulnerabilities of male migrants travelling alone on their journey to Europe. Soc Sci Med 2018;209:86-94.

13. TBMM, insan haklarını inceleme komisyonu mülteci hakları A. komisyonu. GÖÇ VE UYUM RAPORU. Ankara/Turkey (2018). Available at: https://www.tbmm.gov.tr/komisyon/insanhaklari/docs/2018/goc_ ve_uyum_raporu.pdf\%0A Accessed December 2, 2018.

14. Wild V, Dawson A. Migration: a core public health ethics issue. Public Health 2018;158:66-70.

15. Dontsov AI. Reasons for migration decision making and migrants security notions. Procedia Soc Behav Sci 2013;86:76-81.

16. de Wit M, Pouwer F, Gemke RJ, Delemarre-van de Waal HA, Snoek FJ. Validation of the WHO-5 Well-being Index (WHO-5) in adolescents with type 1 diabetes. Diabetes Care 2007;30:2003-2006.

17. Sibai AM, Chaaya M, Tohme RA, Mahfoud Z, Al-Amin H. Validation of the Arabic version of the 5-item WHO well being index in elderly population. Int J Geriatr Psychiatry 2009;24:106-107.

18. Skevington S, Lotfy M, O'Connell KA. The World Health Organization's WHOQOL-BREF quality of life assessment: psychometric properties and results of the international field trial. A Report from the WHOQOL Group. Qual Life Res 2004;13:299-310.

19. Ohaeri JU, Awadalla A. The reliability and validity of the short version of the WHO Quality of Life Instrument (WHOQOL-Bref) in an Arab general population sample. Ann Saudi Med 2009;29:98-104.

20. Önal A, Keklik B. A Study on the problems encountered by refugees and asylum seekers in their access to healthcare services in Isparta province. Süleyman Demirel Univ Vision J 2016;7:132-148.

21. George U, Thomson MS, Chaze F, Guruge S. Immigrant mental health, a public health issue: looking back and moving forward. Int J Environ Res Public Health 2015;12:13624-13648.

22. Steel JL, Dunlavy AC, Harding CE, Theorell T. The psychological consequences of pre-emigration trauma and post-migration stress in refugees and immigrants from Africa. J Immigr Minor Heal 2017;19:523-532.

23. Zaazaa A. Escaping Europe: Why Someone Syrian Refugees Have Chosen to Leave, news deeply (2017). Available at: https://www.newsdeeply.com/syria/articles/2017/12/04/escaping-europe-why-somesyrian-refugees-have-chosen-to-leave. Accessed December 13, 2019.

24. Kim IH, Noh S. Changes in life satisfaction among Korean immigrants in Canada. Int J Cult Ment Health 2014;8:60-71.

25. Taylor DM, Usborne E. When I know who "We" are, I can be "Me": the primary role of cultural identity clarity for psychological well-being. Transcult Psychiatry 2010;47:93-111.

26. Beiser M, Cargo M, Woodbury MA. A comparison of psychiatric-disorder in different cultures - depressive typologies in Southeast-Asian refugees and resident Canadians. Int J Methods Psychiatr Res 1994; 4:157-172.

27. Pajic S, Ulceluse M, Kismihók G, Mol ST, den Hartog DN. Antecedents of job search self-efficacy of Syrian refugees in Greece and the Netherlands. J Vocat Behav 2018;105:159-172.

28. Li SS, Liddell BJ, Nickerson A. The relationship between post-migration stress and psychological disorders in refugees and asylum seekers. Curr Psychiatry Rep 2016;18:82.

29. Sulaiman-Hill C, Thompson S. Afghan and Kurdish refugees, 8-20 years after resettlement, still experience psychological distress and challenges to well being. Aust N Z J Pub Health 2012;36:126-134.

30. Cengiz I, Ergun D, Cakici E. Posttraumatic stress disorder, posttraumatic growth and psychological resilience in Syrian refugees: Hatay, Turkey. Anatol J Psychiatry 2019;20:269-276. 